\title{
Difference of Microfeatures among Diagenetic Facies in Tight Sandstone Reservoirs of the Triassic Yanchang Formation in the Midwestern Region, Ordos Basin
}

\author{
Jian Shi $\mathbb{D}^{1,2}$ Xiaolong Wan, ${ }^{1,2}$ Qichao Xie, ${ }^{1,2}$ Shuxun Zhou, ${ }^{1,2}$ Yan Zhou, ${ }^{3}$ Dazhong Ren $\left(\mathbb{D},{ }^{4}\right.$ \\ and Rongjun Zhang ${ }^{4}$ \\ ${ }^{1}$ Exploration and Development Research Institute of PetroChina Changqing Oilfield Company, Xi'an, Shaanxi 710018, China \\ ${ }^{2}$ National Engineering Laboratory for Exploration and Development of Low-Permeability Oil \& Gas Fields, Xi'an, \\ Shaanxi 710018, China \\ ${ }^{3}$ CNPC Logging Applied Research Institute, Xi'an 710077, China \\ ${ }^{4} X i$ 'an Key Laboratory of Tight Oil (Shale Oil) Development, Xi'an Shiyou University, Xi'an, Shaanxi 710065, China
}

Correspondence should be addressed to Jian Shi; shijian2371@163.com

Received 28 June 2021; Accepted 14 August 2021; Published 2 September 2021

Academic Editor: Feng Xiong

Copyright $@ 2021$ Jian Shi et al. This is an open access article distributed under the Creative Commons Attribution License, which permits unrestricted use, distribution, and reproduction in any medium, provided the original work is properly cited.

\begin{abstract}
Based on the background of sedimentary characteristics, a large amount of core and thin section analysis, taking Chang 6 reservoir of Yanchang Formation in the central and western Ordos Basin as an example, through the application of scanning electron microscopy, high-pressure mercury injection, nuclear magnetic resonance and microscopic water drive oil model, and other experimental test methods, the diagenetic facies types and microscopic pore structure characteristics of tight sandstone reservoirs are discussed and analyzed in depth. The results show that the average porosity loss rate caused by early diagenesis compaction in the study area is $50.62 \%$, which is the main reason for reservoir compactness. The cementation further causes porosity loss, and the later dissolution increases the reservoir space in the study area to a certain extent. Different diagenetic facies reservoirs not only have obvious differences in porosity evolution characteristics but also have significant differences in pore throat radius distribution characteristics, movable fluid occurrence characteristics, and water drive oil characteristics. The pore throat distribution with radius greater than $R_{50} \sim R_{60}$ determines the permeability. The difference in movable fluid saturation mainly depends on the connectivity of the relative large pore space corresponding to the relaxation time greater than the cut-off value of $T_{2}$. The size of pore throat radius has a good control effect on water flooding efficiency.
\end{abstract}

\section{Introduction}

In recent years, with the decreasing of conventional oil and gas resources, the world has increased the exploration and development of unconventional energy, especially tight oil and gas [1-9]. Compared with conventional sandstone reservoirs, tight sandstone reservoirs are characterized by small pore throats (micro- and nanoscale), complex pore structure, and strong micro- and macroheterogeneity [10]. Among them, the pore microstructure, pore type, pore evolution and control factors, and reservoir performance parameters have become the focus of tight oil reservoir research $[11,12]$. The Ordos Basin is an early area of tight oil and gas exploration and development in China. The tight oil and gas resources are very rich and have broad prospects for exploration and development [13-15]. The Ordos Basin is the second largest sedimentary basin in my country. It is structurally located on the western edge of the North China Craton $[16,17]$. The internal structure of the basin is relatively simple and the stratum is relatively gentle. The overall appearance is large monoclinic with wide and gentle on the east flank and steep and narrow on the west flank (Figure 1).

During the deposition process of Yanchang Formation in the Ordos Basin, the target reservoir rocks were 


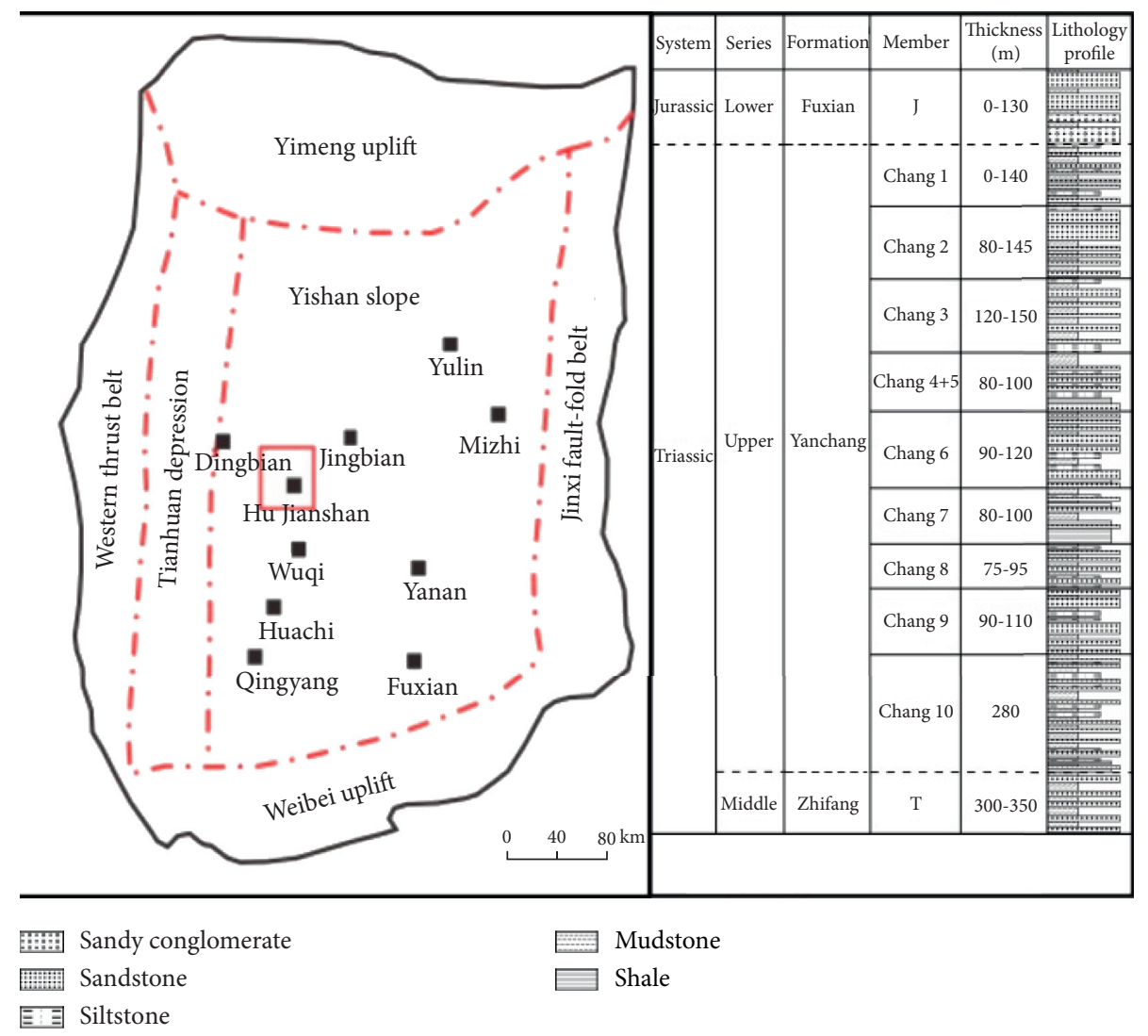

Figure 1: Geographical location of the midwestern regions, Ordos Basin.

compacted due to compaction and cementation, and a large number of micro- and nanoscale pore throats developed [18-20]. The types and distribution characteristics of micropore throats restrict the quality and development effect of tight sandstone reservoirs. Due to the different degree of diagenesis, the micropore throat parameters of tight sandstone reservoirs are significantly different. Even if the permeability level is the same, the pore throat parameters and distribution law may also show different characteristics. The complex pore throat structure characteristics lead to the changeable occurrence state and distribution characteristics of fluid in the pore throat, which directly restricts the next exploration and development. Therefore, it is necessary to analyze the microscopic pore structure characteristics under different diagenesis, hoping to provide reference for the optimization of high quality target areas of tight sandstone reservoirs. Based on the auxiliary experimental results of casting thin section, scanning electron microscope, X-ray diffraction, and cathodoluminescence, the microscopic pore structure and seepage characteristics of the study area were studied by high-pressure mercury injection, nuclear magnetic resonance, and microscopic water flooding experiments. The differences of microscopic characteristics of different diagenetic phases were analyzed, and the main influencing factors of microscopic characteristics were clarified, so as to provide guidance for further understanding the heterogeneity of tight sandstone reservoirs and evaluating the effective reservoir distribution.

\section{Experimental Principle and Sample Information}

2.1. Pore Throat Structure Test. The mercury injection experiment is one of the important methods to analyze the microscopic pore throat structure of the reservoir. The high-pressure mercury intrusion experiment is based on the Washburn equation by converting the mercury entry or exit pressure and the pore diameter to achieve different pore diameters and mercury entry saturations. The corresponding relationship between the pore size distribution characteristics is further obtained. It is widely used to obtain reservoir microscopic pore structure parameters based on high-pressure mercury intrusion experiments to characterize reservoir quality $[21,22]$. The high-pressure mercury intrusion experiment adopts AutoPore IV9510 automatic mercury intrusion instrument from Mike Company, the maximum working pressure of the instrument is $414 \mathrm{MPa}$, and the measuring range of pore throat radius is $0.003 \sim 1000 \mu \mathrm{m}$.

2.2. Movable Fluid Occurrence Test. Place the fluid-containing sample in a static magnetic field, and start to make the hydrogen nuclei contained in the fluid in the rock sample show nuclear magnetic resonance with a suitable radio frequency pulse. Remove the effect of the radio frequency pulse on the rock sample, and the hydrogen nuclei will immediately 
release energy and appear. For nuclear magnetic resonance signals with a gradual decrease in energy, the time corresponding to this process is the relaxation time $[23,24]$, and the $T_{2}$ spectrum curve characteristics of the transverse $T_{2}$ relaxation time and $T_{2}$ attenuation are usually used for movable fluid occurrence and pore throat analysis of distribution. Different pore sizes have different corresponding relaxation times. The larger the $T_{2}$ relaxation time, the larger the pore size, and on the contrary, the smaller the pore. Therefore, the $T_{2}$ spectrum can be used to reflect the development of the pore radius. Since the pore radius is too small, a large capillary force will obstruct the fluid flow and be constrained. At this time, the corresponding $T_{2}$ relaxation time is the $T_{2}$ cut-off value ( $\left.T_{2 \text { cutcfff }}\right)$. The fluid that is less than the cut-off value of $T_{2}$ is called immovable fluid, and when it is more, it is called movable fluid. Nuclear magnetic resonance $T_{2}$ spectrum measurement uses RecCore-3000 nuclear magnetic resonance core analyzer, the system frequency is $2 \sim 5 \mathrm{MHz}$ continuously adjustable, the magnetic induction intensity is $0.0940 \sim 0.1175 \mathrm{~T}$, and the frequency accuracy is $0.01 \mathrm{~Hz}$.

2.3. Microscopic Water Driving Oil Test. First, the core sample is made into a thin slice model of approximately $2.5 \mathrm{~cm} \times 2.5 \mathrm{~cm} \times 0.05 \mathrm{~cm}$, and fluids that simulate crude oil and formation water are prepared according to the viscosity of the crude oil and the salinity of formation water in the study area, and dyes are added to dye red and blue, respectively. It is convenient to distinguish under the electron microscope. Make the simulated oil and simulated water flow into the sample model under a certain pressure. Through the use of electron microscope and microscopic image acquisition technology to observe the seepage mode and displacement effect of oil and water in the microscopic pore structure of the sample, it can intuitively reflect the characteristics of oil and water in the microscopic pore structure [25]. This microwater drive oil experiment was mainly implemented at the State Key Laboratory of Continental Dynamics of Northwest University through real sandstone microwater drive experiment equipment.

2.4. Sample Information. The tight sandstone reservoirs of the Yanchang Formation in the central and western regions of the Ordos Basin developed delta front subfacies deposits. From the experimental analysis of core physical properties, casting thin sections, scanning electron microscope, and cathodoluminescence of 180 core samples, it is known that the rock types are mainly feldspar sandstone, lithic feldspar sandstone, and feldspar lithic sandstone. Select 10 representative samples from them to further carry out the experimental analysis of high-pressure mercury intrusion, nuclear magnetic resonance, and microscopic water flooding models (Table 1).

\section{Diagenesis Characteristics}

\subsection{Diagenesis Types}

3.1.1. Compaction. In the early stage of diagenesis, the loose clastic minerals of the sediments due to the overlying pressure were gradually compacted to close contact. During the process, the pore water was discharged one after another and slowly consolidated into rock. Compaction played an important role after the sand body was deposited. With the deepening of burial, detrital particles often exhibit directional arrangement, close contact relationship, multiple rigid fractures, multiple plastic deformations, etc., and at the same time, a large number of pores are reduced. It will cause great damage to the storage space and seepage capacity of the reservoir, which is an important reason for the deterioration of the reservoir quality. The controlling factors are mainly the pressure of the overlying formation, the ratio of impurity bases, and the compressive resistance of particles [26-28]. Through the observation of thin slices under the microscope, it can be found that the rigid quartz particles exhibit directional arrangement, and the particles are mostly pointline and line contact relationships. In some samples, it can be found that the particles are in concave-convex contact relationship and the phenomenon of particle fracture (Figure 2(a)). Plastic minerals such as plastic cuttings and mica have relatively soft characteristics and are prone to deforming during the compaction process and fill in the particle space, thereby affecting the porosity (Figure 2(b)).

3.1.2. Cementation. Cementation is the effect of the fluid in the rock consolidating the clastic minerals, causing pore blockage in the process, which is the main reason for the further destruction of the physical properties of the reservoir. The cementation in the study area is more obvious, mainly including authigenic clay minerals, carbonates, and siliceous cements.

(1) Clay Mineral Cementation. The formation of clay minerals is mainly determined by the mineral composition, fluid characteristics, and temperature conditions. There are various types of clay minerals in the study area, with high content of chlorite, illite, and kaolinite.

Through the microscopic identification, the chlorite in the study area is mainly attached to the surface of the particles in the shape of a crust, which develops in the shape of small sharp flakes or scales (Figure 2(c)), and the chlorite is continuously distributed in a film shape (Figure 2(d)). It can not only consolidate the particles, but also have a certain protective effect on the particles and pores. However, a large number of developed chlorites are often easy to fill small pores and even throats, causing physical damage.

The illite cementation in the study area is generally developed, mainly in the form of thin film filaments and bridges, which occur in the intergranular pores, often divided into pores and roars, and the overall continuity is poor (Figures 2(e) and 2(f)). Illite easily cuts the pore space, thereby reducing the connectivity between each other, causing the pores to become micropores, and the throats are mostly blocked, which reduces the storage performance and seepage capacity of the reservoir to a certain extent.

The study area is dominated by authigenic kaolinite, with good crystal shape, mostly in the form of hexagonal plate and vermicular aggregates filled in the pore space 
TABLE 1: Sample information table.

\begin{tabular}{|c|c|c|c|c|c|c|c|}
\hline $\begin{array}{l}\text { Well } \\
\text { number }\end{array}$ & $\begin{array}{l}\text { Depth, } \\
\text { m }\end{array}$ & $\begin{array}{c}\text { Porosity, } \\
\%\end{array}$ & $\begin{array}{l}\text { Gas permeability, } \\
\times 10^{-3} \mu \mathrm{m}^{2}\end{array}$ & Experimental test & Rock type & $\begin{array}{l}\text { Sedimentary } \\
\text { facies }\end{array}$ & Horizon \\
\hline A144 & 2193.9 & 9.39 & 0.098 & \multirow{3}{*}{$\begin{array}{l}\text { Microscopic water driving } \\
\text { oil, NMR }\end{array}$} & \multirow{5}{*}{$\begin{array}{l}\text { Feldspar } \\
\text { sandstone }\end{array}$} & \multirow{10}{*}{$\begin{array}{l}\text { Deltaic front } \\
\text { subfacies }\end{array}$} & \multirow{8}{*}{ Chang 6} \\
\hline H393 & 2247.3 & 10.80 & 0.253 & & & & \\
\hline A36 & 1945.2 & 10.8 & 0.137 & & & & \\
\hline Y182 & 2101.2 & 12.3 & 0.083 & \multirow{4}{*}{ HPMI } & & & \\
\hline A211 & 1922.6 & 8.9 & 0.058 & & & & \\
\hline Y144 & 2178.4 & 8.4 & 0.027 & & Lithic feldspar & & \\
\hline $\mathrm{H} 185$ & 2226.5 & 11.75 & 0.085 & & sandstone & & \\
\hline $\mathrm{H} 248$ & 2037.1 & 10.08 & 0.023 & \multirow{3}{*}{$\begin{array}{l}\text { Microscopic water driving } \\
\text { oil, NMR }\end{array}$} & & & \\
\hline A296 & 2197.6 & 10.6 & 0.126 & & Feldspar lithic & & \multirow{2}{*}{ Chang 8} \\
\hline $\mathrm{H} 26$ & 2199.9 & 6.4 & 0.016 & & sandstone & & \\
\hline
\end{tabular}
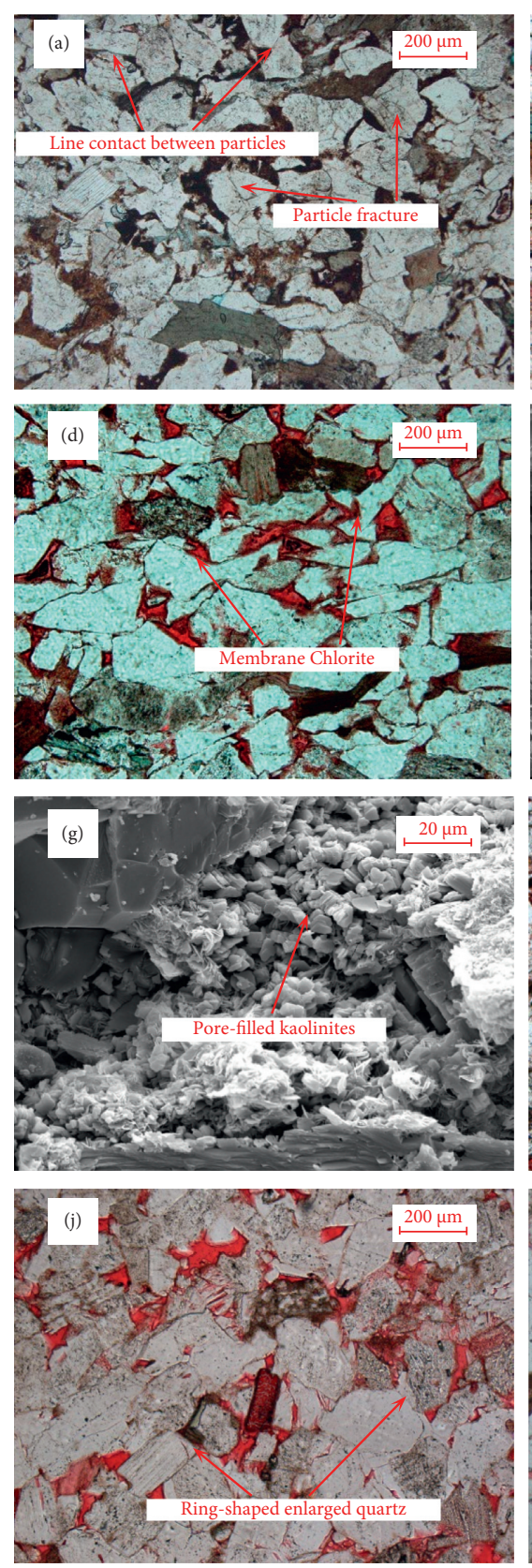
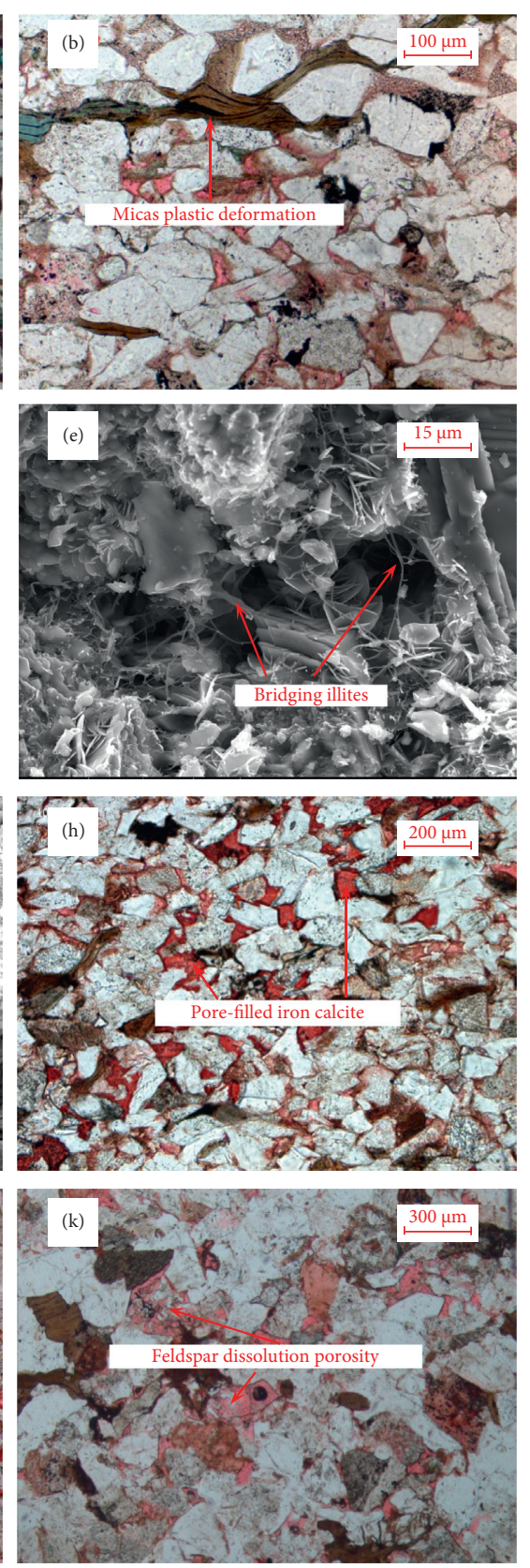
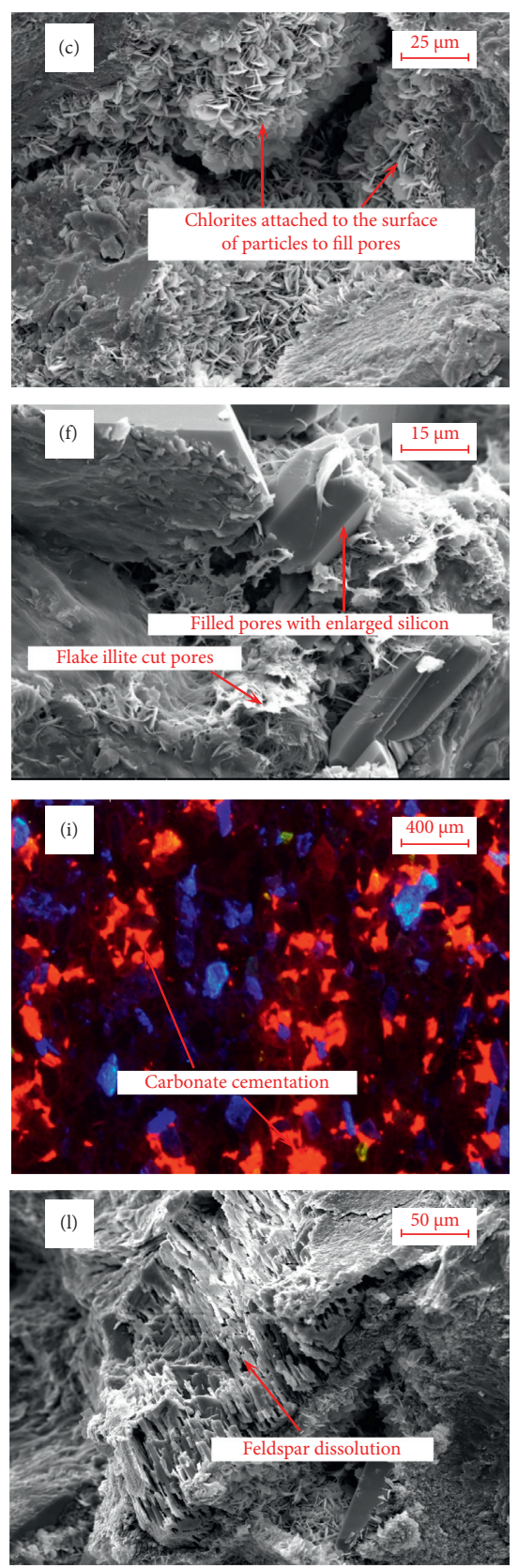

FIGURE 2: Microscope figures of typical diagenetic phenomena of samples. 
(Figure 2(g)), which is mostly found in primary intergranular pores and intergranular dissolved pores. Kaolinite cement blocks the pores, resulting in a reduction in pore space and a more complex pore structure. At the same time, the porosity and seepage rate of the reservoir are reduced and the heterogeneity of the reservoir is enhanced. However, kaolinite has more developed intercrystalline pores, which can increase the micropores in the pore space, and it often appears dark brown under thin-film microscope.

(2) Carbonate Cementation. Using the statistics of the thin slice experiment data of the sample and the observation under the microscope, it is found that different degrees of carbonate cementation and filling of pores have occurred in the study area. The cementation is dominated by iron calcite (Figure 2(h)). The pores are filled by carbonate, which leads to the loss of a large amount of pore space, and the structure between particles is more complex and diverse.

The carbonate in the early diagenesis is mainly calcite in the form of micrite and microcrystalline. When the carbonate ions in the early pore medium reach the saturated state, the early carbonate cement will be precipitated, resulting in a large amount of filling of the pore space. However, calcite filling also improves the ability of sandstone to resist compaction to a certain extent and plays a certain role in the formation of secondary pores for subsequent dissolution. In the middle and late stages, iron ions are often precipitated due to the mutual transformation between rock cuttings and other dark minerals and clay minerals, which are easy to form with the calcite formed in the early stage. The iron calcite is distributed in intergranular pores and dissolved pores (Figure 2(i)), making the reservoir rock dense.

(3) Silicone Cementation. The siliceous cementation in the study area is mainly manifested by the development of secondary quartz enlargement and authigenic quartz. The secondary enlargement of grade II and III quartz is more common under the microscope, and the edge of the quartz grain is locally developed (Figure $2(\mathrm{j})$ ), and the ring edge is rare. Its formation is mainly related to the mutual transformation of clay minerals and the dissolution of silicate minerals and is controlled by the size of the growth space. It is more common in sandstone reservoirs with small interstitial content. The development of secondary enlarged edges occupies part of the intergranular pore space, which is not conducive to the preservation of intergranular pores. In addition, under the scanning electron microscope, it can be seen that the quartz particles surrounded by the chlorite film have enlarged quartz edges where the local chlorite film is not developed. The authigenic quartz crystals are often filled in the residual intergranular pores.

3.1.3. Corrosion. According to the casting thin section of the sample and the statistics of the experimental data of the scanning electron microscope and the observation under the microscope, the dissolution in the study area is mainly the dissolution of feldspar (0.78\%), followed by the dissolution of cuttings $(0.13 \%)$. The total content of dissolved pores accounts for $28.6 \%$ of the total porosity, which improves the reservoir performance and pore-throat connectivity to a certain extent. Feldspar is dissolved to produce secondary dissolution pores (Figure 2(k)), which often dissolve along the joint surface (Figure 2(l)). Some feldspars may disappear due to the excessively strong dissolution degree, and the dissolution of lithic debris can be seen locally.

\subsection{Evolution Characteristics of Porosity}

3.2.1. The Influence of Diagenesis on Porosity. Quantitative analysis of compaction is carried out by calculation of porosity after porosity. After compaction, the remaining porosity can be used for the current cement content, intergranular pore content, micropore content, measured porosity, and the total displayed under the thinfilm microscope. The correlation between the porosity contents is brought into formulas (i)-(iii) in Table 2, and the porosity after compaction can be calculated. According to the contact relationship between particles and cement observed under the microscope, it can help to divide the sequence of the development of different cements, and start to develop with strong dissolution as the boundary, and divide the cement into early and midlate. In the early stage, it was mainly thin-film chlorite, grade I quartz secondary enlargement, calcite, and other cements. In the middle and late stages, it was mainly grade II III quartz ring enlargement edge, pom-shaped chlorite, kaolinite, iron calcite, illite, etc. Putting the relevant volume fraction into formulas (iv) and (v) in Table 2, the lost porosity and porosity of the early cementation and the middle and late cementation can be obtained, respectively. The increase in porosity and porosity increase rate due to dissolution are given in formulas (vi) and (vii) in Table 2.

The calculation results show (Table 3) that the sorting coefficient is mainly distributed between 1.11 and 1.73, with an average of 1.43 , which is biased towards fineness. The main distribution range of the initial porosity is $32.96 \%$ $39.68 \%$, with an average of $36.92 \%$, showing a nearly normal distribution, slightly biased towards the roughness. The remaining porosity after compaction in the early diagenesis is mainly distributed between $10.23 \%$ and $30.14 \%$, with an average of $18.51 \%$, and the porosity loss rate is between $30.22 \%$ and $73.83 \%$, with an average of $50.62 \%$. The remaining porosity distribution ranges from $3.39 \%$ to $10.52 \%$ after cementation, with an average of $8.13 \%$. The porosity loss caused by early cementation and metasomatism ranges from $1.13 \%$ to $14.72 \%$, with an average of $3.96 \%$. The porosity distribution of the middle and late cementation loss ranges from $2.25 \%$ to $13.1 \%$, with an average of $6.42 \%$. The secondary dissolution porosity produced by dissolution is $0.34 \sim 7.47 \%$, with an average of $2.26 \%$. It shows that when the pore volume of the reservoir is greatly reduced, the dissolved pores increase the storage space of the reservoir in the study area to a certain extent. However, the wider distribution range has strong uneven characteristics. 
TABLE 2: Quantitative calculation method of sandstone porosity evolution.

\begin{tabular}{|c|c|c|}
\hline $\begin{array}{l}\text { Porosity evolution } \\
\text { parameter }\end{array}$ & Formula & Remarks \\
\hline Initial porosity & $\Phi_{1}=20.91+22.9 / S_{d}(\mathrm{i})$ & $\begin{array}{l}\Phi_{1} \text { represents the original porosity of the unconsolidated sandstone, \%; } S_{d} \\
\text { represents the Trask sorting coefficient, } S_{d}=\left(P_{25} / P_{75}\right)^{1 / 2} \text { (in which } P_{25} \text { and } P_{75} \\
\text { represent the corresponding granular diameter of } 25 \% \text {-in-content particles and } \\
75 \% \text {-in-content particles in the accumulative granularity curve, respectively, mm) }\end{array}$ \\
\hline $\begin{array}{l}\text { Porosity after } \\
\text { compaction }\end{array}$ & $\begin{array}{c}\Phi_{2}=C+\left(P_{1}+P_{2}\right) \times P_{3} / P_{4} \\
\quad(\text { ii }) \\
F_{a}=\left(\Phi_{1}-\Phi_{2}\right) / \Phi_{1}\end{array}$ & $\begin{array}{l}\Phi_{2} \text { represents the porosity after compaction, } \% ; C \text { represents the cement content, } \\
\% ; P_{1} \text { represents the surface porosity of intergranular pores, } \% ; P_{2} \text { represents the } \\
\text { surface porosity of original micropores, } \% ; P_{3} \text { represents the measured porosity of } \\
\text { the sample, } \% ; P_{4} \text { represents the total surface porosity, } \% ; P_{a} \text { represents the } \\
\text { porosity loss due to compaction, } \% ; F_{a} \text { represents the ratio of porosity loss due to } \\
\text { compaction, } \%\end{array}$ \\
\hline $\begin{array}{l}\text { Porosity after } \\
\text { cementation }\end{array}$ & $\begin{array}{c}\Phi_{3}=\Phi_{2}-C \text { (iv) } \\
F_{b}=\left(\Phi_{2}-\Phi_{3}\right) \times 100 \% / \Phi_{1} \\
(\mathrm{v})\end{array}$ & $\begin{array}{c}\Phi_{3} \text { represents the porosity after compaction and cementation, } \% ; F_{b} \text { represents the } \\
\text { ratio of porosity loss due to cementation, } \%\end{array}$ \\
\hline $\begin{array}{l}\text { Dissolution increases } \\
\text { porosity }\end{array}$ & $\begin{array}{c}\Phi_{4}=P_{5} \times P_{3} / P_{4}(\mathrm{vi}) \\
F_{c}=\Phi_{4} \times 100 \% / \Phi_{1}(\mathrm{vii})\end{array}$ & $\begin{array}{c}\Phi_{4} \text { represents the increased porosity due to dissolution, } \% ; P_{5} \text { represents the total } \\
\text { dissolution pore surface area, } \% ; F_{c} \text { represents the ratio of porosity loss due to } \\
\text { dissolution, } \%\end{array}$ \\
\hline
\end{tabular}

TABle 3: Statistics of porosity evolution in diagenesis.

\begin{tabular}{|c|c|c|c|c|c|c|c|c|}
\hline \multirow{3}{*}{ Compaction } & \multicolumn{2}{|c|}{ Initial porosity, $\%$} & \multicolumn{3}{|c|}{ Porosity after compaction, $\%$} & \multicolumn{3}{|c|}{$\begin{array}{l}\text { The ratio of porosity loss due to } \\
\text { compaction, } \%\end{array}$} \\
\hline & Range & Average & Range & & Average & & & Average \\
\hline & $32.96 \sim 39.68$ & 36.87 & $10.23 \sim 30.14$ & & 18.43 & 30.2 & 73.83 & 50.54 \\
\hline \multirow{3}{*}{ Cementation } & \multicolumn{2}{|c|}{$\begin{array}{l}\text { Porosity loss due to early } \\
\text { cementation, } \%\end{array}$} & \multicolumn{3}{|c|}{$\begin{array}{c}\text { Porosity loss due to the midlate } \\
\text { cementation, } \%\end{array}$} & \multicolumn{3}{|c|}{$\begin{array}{l}\text { Porosity after compaction and } \\
\text { cementation, } \%\end{array}$} \\
\hline & Range & Average & Range & & Average & & & Average \\
\hline & $1.13 \sim 14.72$ & 3.96 & $2.25 \sim 13.1$ & & $6.42^{\circ}$ & 3.3 & 0.52 & 8.19 \\
\hline \multirow{3}{*}{ Corrosion } & \multicolumn{2}{|c|}{$\begin{array}{l}\text { Increased porosity due to } \\
\text { dissolution, } \%\end{array}$} & \multicolumn{2}{|c|}{$\begin{array}{l}\text { Final calculation of } \\
\text { porosity, } \%\end{array}$} & \multicolumn{2}{|c|}{$\begin{array}{c}\text { Porosity measured by } \\
\text { gas, } \%\end{array}$} & \multicolumn{2}{|c|}{ Error, \% } \\
\hline & Range & Average & Range & Average & Range & Average & Range & Average \\
\hline & $0.34 \sim 7.47$ & 2.21 & $4.82 \sim 13.87$ & 10.33 & $4.35 \sim 16.77$ & 10.75 & $0.79 \sim 20.3$ & 6.89 \\
\hline
\end{tabular}

3.2.2. Porosity Evolution Differences of Different Types of Diagenetic Facies. On the basis of thin section observation and identification data analysis and statistics, by analyzing the response correlation between different mineral characteristics, pore types and distribution characteristics, and macro- and microcharacteristics, the main control minerals, pore types, and other characteristics are shown. Four types of diagenetic facies are divided: the residual chloritemembrane intergranular-pore diagenetic facies, the feldspar dissolution diagenetic facies, the clay mineral cemented microporous diagenetic facies, and the carbonate cemented tight diagenetic facies (Figure 3 ).

Formulas (i) (vii) in Table 2 are used to establish the porosity evolution simulation equations of four different diagenetic facies in the study area. Through the above studies, it is found that, according to the diagenetic evolution process, a large number of minerals and fluids continue to resist compaction, fill pores, and dissolve particles in the pore space of sediments. However, the effects of different diagenesis in different regions and environments are also different, which can be proved by the porosity evolution characteristics of diagenetic facies. The final calculated porosity of residual chlorite-membrane intergranular-pore diagenetic facies is $12.28 \%$. The dissolution porosity of feldspar dissolution diagenetic facies increased the most, with an average of $3.95 \%$. Clay mineral cemented microporous diagenetic facies lost the most porosity due to the middle and late cementation, with an average of $8.11 \%$. The compaction of carbonate cemented tight diagenetic facies leads to the smallest loss of porosity, while the early cementation leads to the largest loss of porosity, which is $17.12 \%$.

\section{Differences in Microscopic Characteristics of Different Diagenetic Facies}

4.1. Differences in Pore Throat Structure. Through the analysis of the size distribution of different types of pore throats and the control of physical properties in Figure 4, it is found that the main peak value of mercury inflow and permeability contribution value of the residual chloritemembrane intergranular-pore diagenetic facies are both at $>1 \mu \mathrm{m}$. The main peak values of mercury inflow and permeability contribution from pore throats of the feldspar dissolution diagenetic facies are both between $0.5 \mu \mathrm{m}$ and $1 \mu \mathrm{m}$. Due to the later cementation, the pore throat of the clay mineral cemented microporous diagenetic facies is seriously damaged, the pore throat configuration is poor, the number of mesopore throats is reduced, the pore throat mercury intake decreases, the cumulative mercury intake 


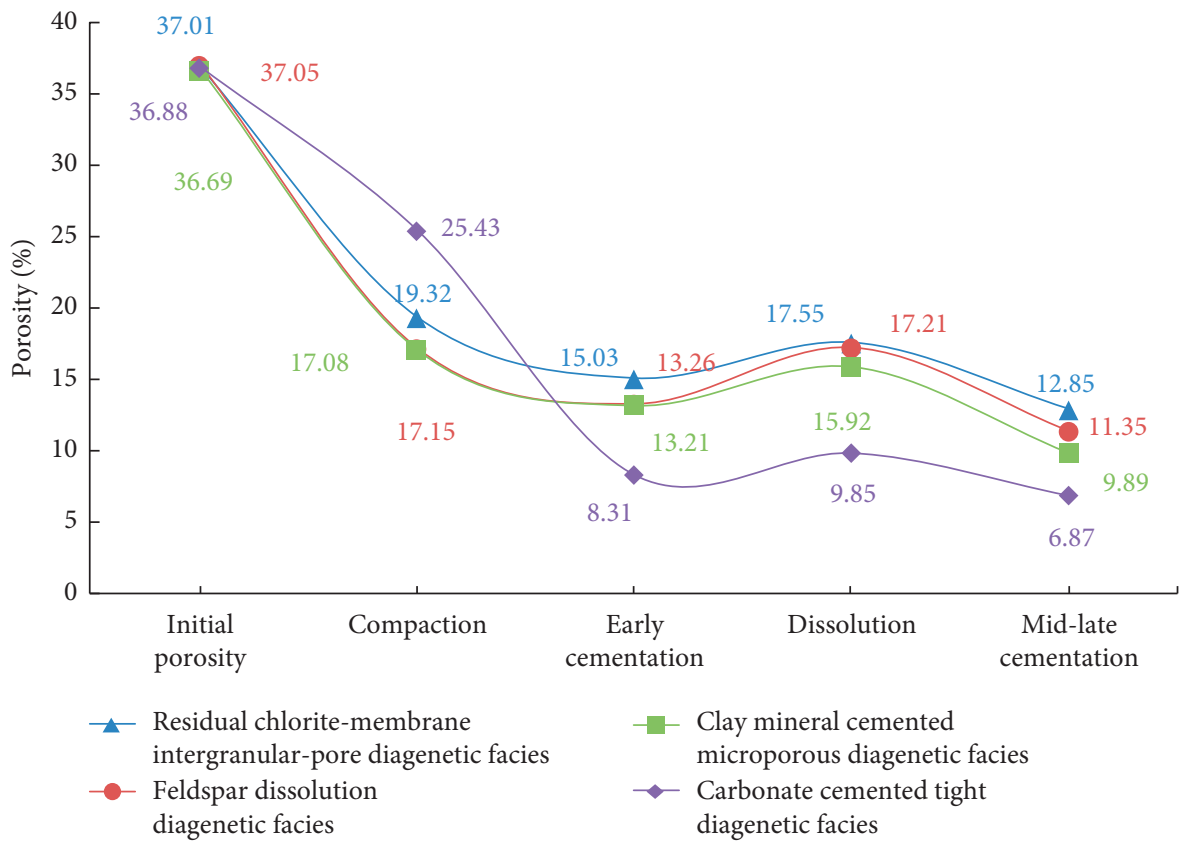

Figure 3: Pore evolution process of different diagenetic facies.

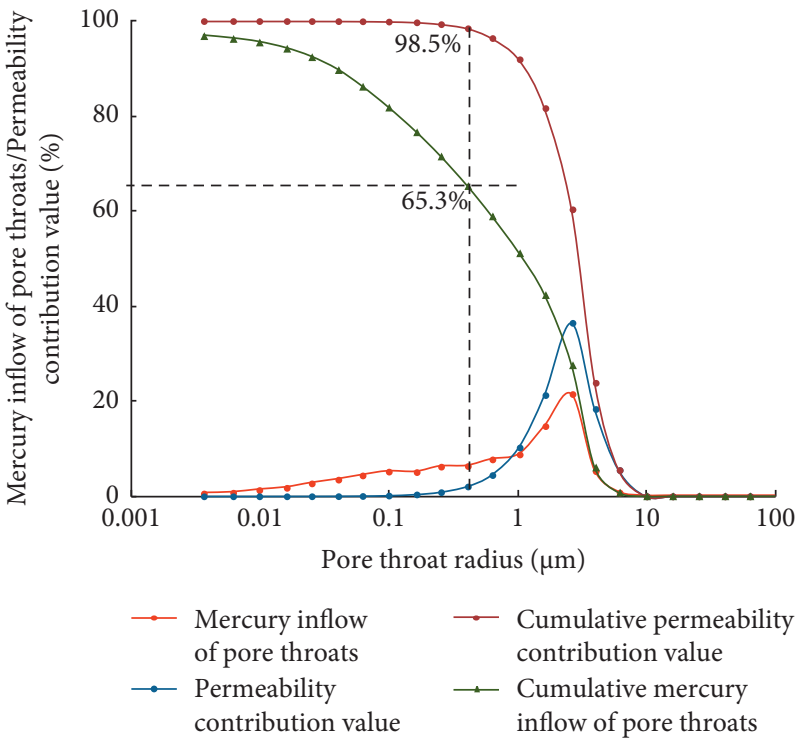

(a)

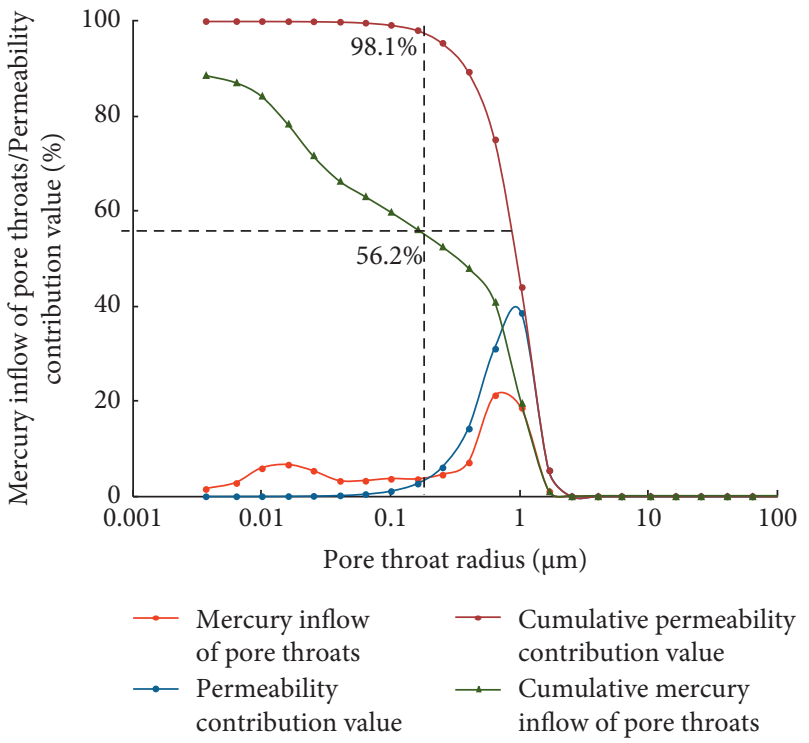

(b)

Figure 4: Continued. 


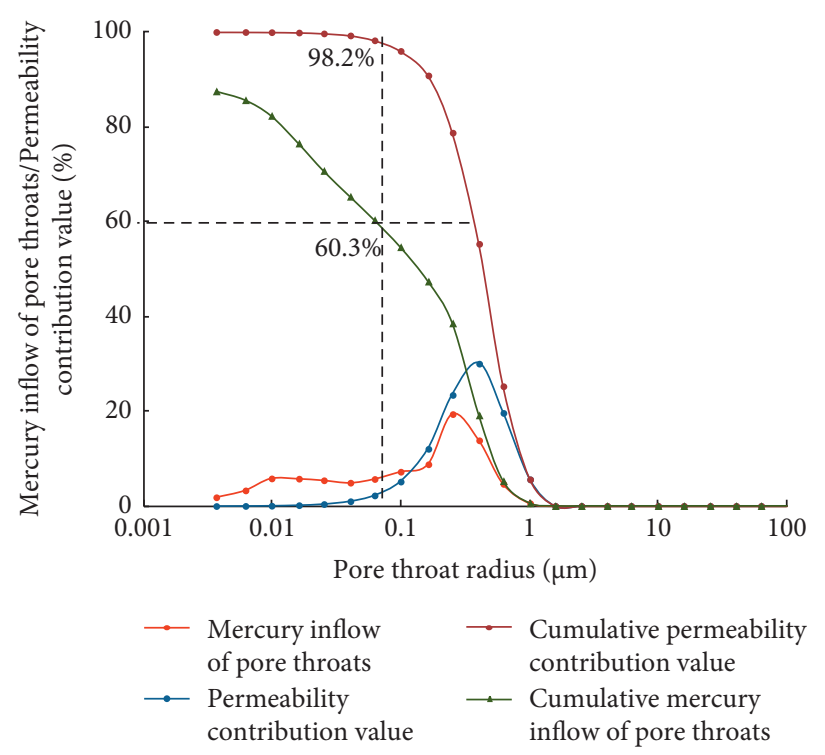

(c)

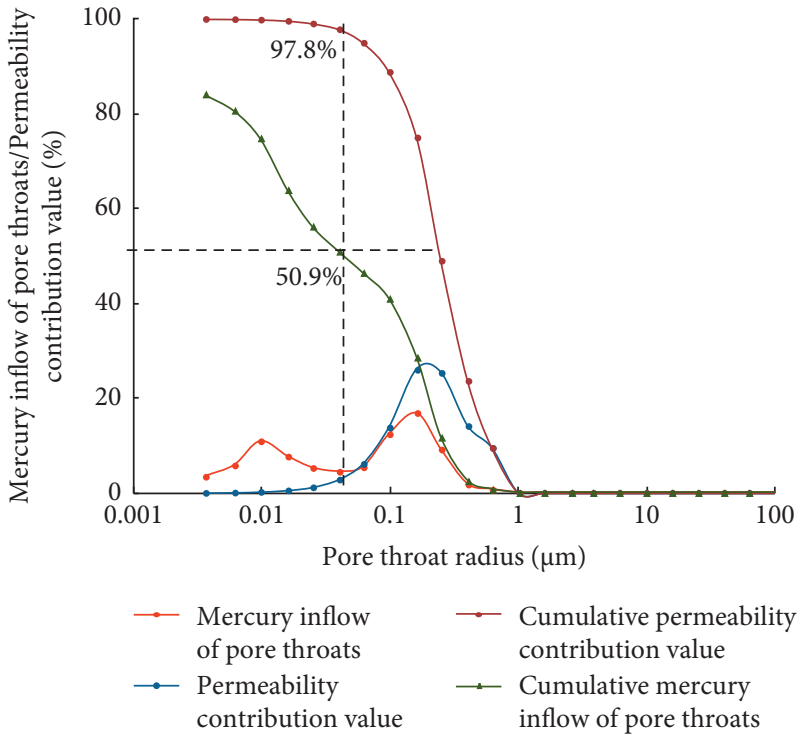

(d)

Figure 4: Different types of pressure curves and pore throat distribution characteristics. (a) Residual chlorite-membrane intergranular-pore diagenetic facies, A3, $1945.2 \mathrm{~m}$. (b) Feldspar dissolution diagenetic facies, Y182, $2101.2 \mathrm{~m}$. (c) Clay mineral cemented microporous diagenetic facies, A211, $1922.6 \mathrm{~m}$. (d) Carbonate cemented tight diagenetic facies, Y144, $2178.4 \mathrm{~m}$.

decreases, and the main peak of the pore throat radius of the contribution value of permeability and permeability is between $0.1 \mu \mathrm{m} \sim 0.5 \mu \mathrm{m}$. The pore throats of the carbonate cemented tight diagenetic facies have almost disappeared. Unimodal is the main morphology that contributes to the pore throat radius interval and permeability. Permeability contribution rate and pore throat mercury ingress are the least. The main peak value of pore throat mercury ingress and permeability contribution value of pore throat radius are both at $<0.1 \mu \mathrm{m}$.

In the initial stage of mercury intrusion experiment, for samples with different permeability, the relatively large pore throat occupies a small proportion. However, the cumulative permeability contribution value rose rapidly to about $98 \%$ within the radius of the large pore throat. The $\mathrm{cu}-$ mulative mercury saturation in this interval is also increasing rapidly, and the curve is relatively steep, but the steepness is not as steep as the cumulative permeability contribution rate. The cumulative mercury saturation achieved in this interval is mainly distributed between $49 \%$ and $66 \%$. Subsequently, mercury continued to enter the sample, and the cumulative permeability contribution curve showed a flat trend with a slow increase rate. However, the increase rate of accumulated mercury saturation did not decrease significantly. It shows that the relatively large pore throat mainly controls the permeability, and the relatively small pore throat has little effect on the permeability, but has a certain storage capacity. Through analysis of mercury intrusion samples in the study area, it was found that the average mercury saturation of about $29.5 \%$ was controlled by relatively small pore throats. The permeability of the study area is mostly controlled by pore throats with a radius larger than $R_{50} \sim R_{60}$.
When the characteristics of mercury injection curves of different diagenetic facies are compared, it is found that the permeability contribution curve shifts to the left as the sample permeability decreases, indicating that the greater the permeability, the larger the proportion of relatively large pore throats, and vice versa. The diagenetic facies pore throat radius distribution is obviously different, which determines the permeability difference.

\subsection{Differences in the Occurrence Characteristics of Movable} Fluids. The movable fluid saturation of the residual chloritemembrane intergranular-pore diagenetic facies samples of the chlorite membrane is the highest, which is $58.5 \%$, of which the movable pore space corresponding to the relaxation time greater than the $T_{2}$ cut-off value is $44.8 \%$, and the movable pore space corresponding to the $T_{2}$ cut-off value is less than $13.7 \%$. The morphological characteristics of the $T_{2}$ spectrum curve before centrifugation showed a double-peak shape with high left and low right, and the $T_{2}$ cut-off value was $4.97 \mathrm{~ms}$. After centrifugation, the morphological characteristics of the $T_{2}$ spectrum curve changed to a near-single peak shape (Figure 5(a)).

The movable fluid saturation of the feldspar dissolution diagenetic facies samples is medium, $35.66 \%$, in which the movable pore space corresponding to the relaxation time greater than the $T_{2}$ cut-off value is $23.6 \%$, and the movable pore space corresponding to the $T_{2}$ cut-off value is $12 \%$. The morphological characteristics of the $T_{2}$ spectrum curve before centrifugation showed a double-peak shape of left high and right low type. After centrifugation, the right peak of the $T_{2}$ spectrum curve decreased to a greater extent (Figure 5(b)). 


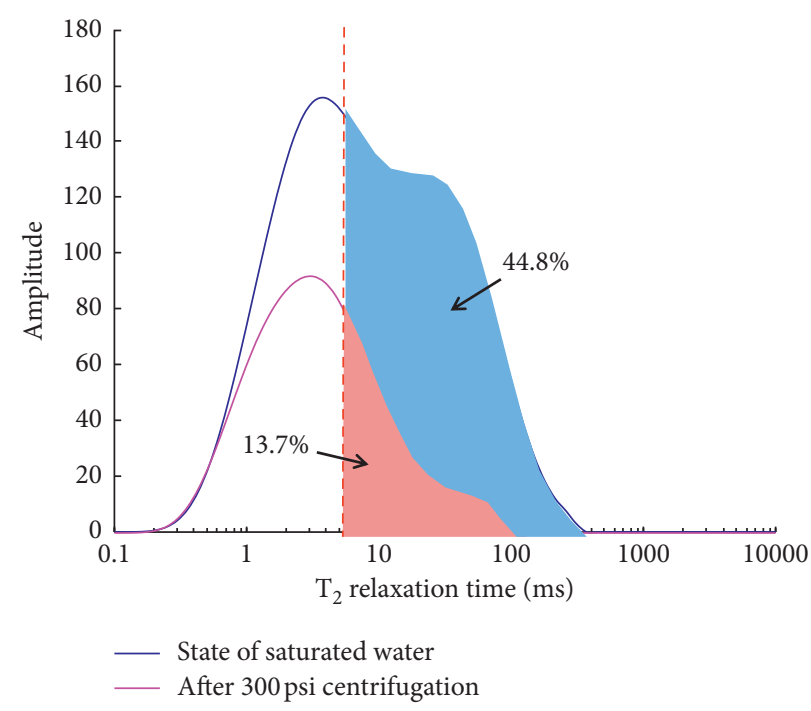

(a)

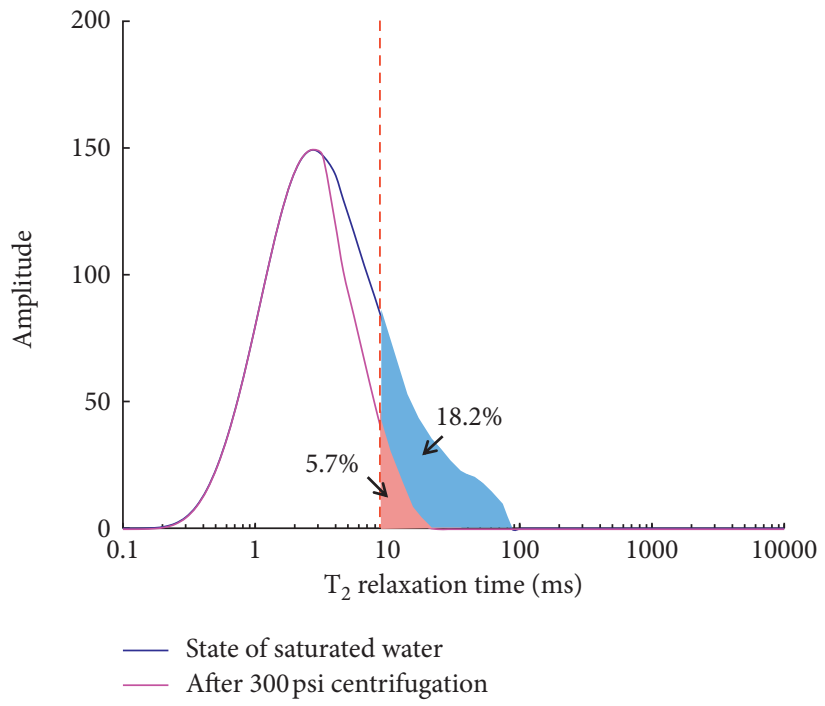

(c)

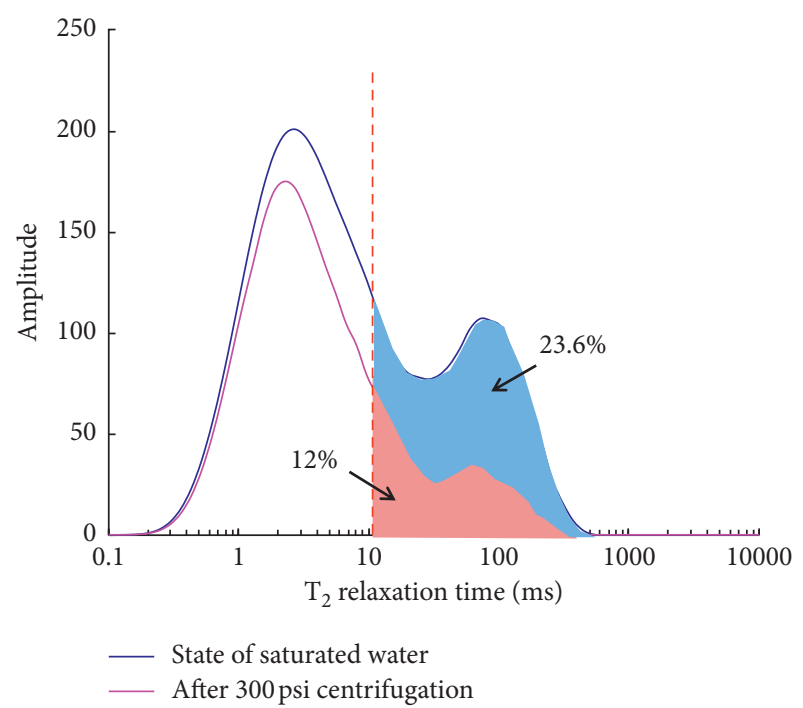

(b)

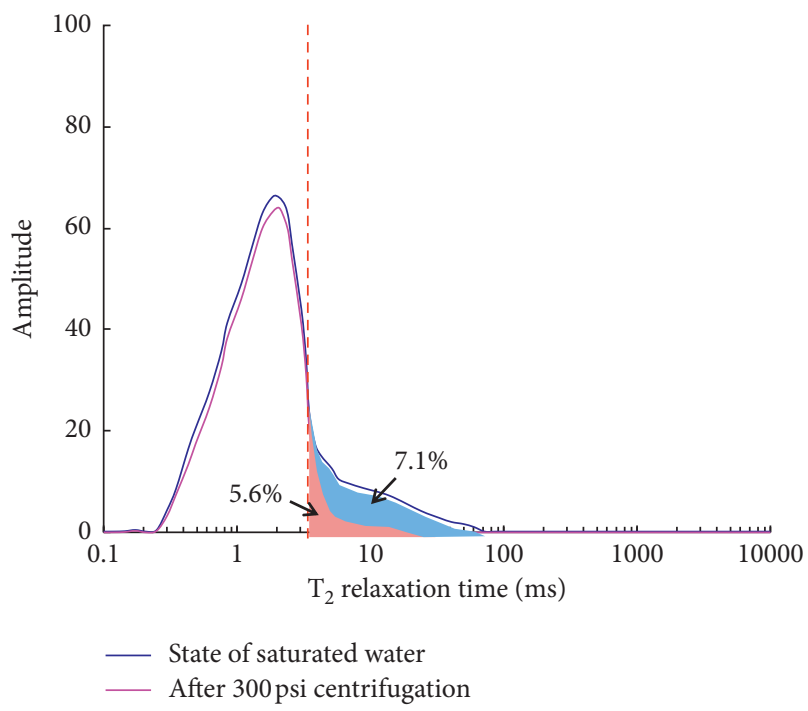

(d)

FiguRE 5: NMR $T_{2}$ spectrum distribution of different diagenetic facies. Note: the blue area is the movable pore space corresponding to the relaxation time greater than the $T_{2}$ cut-off value, the pink area is the movable pore space corresponding to the relaxation time less than the $T_{2}$ cut-off value, and the dashed line is the $T_{2}$ cut-off value. (a) Residual chlorite-membrane intergranular-pore diagenetic facies, H393, $2247.3 \mathrm{~m}$. (b) Feldspar dissolution diagenetic facies, H185, $226.5 \mathrm{~m}$. (c) Clay mineral cemented microporous diagenetic facies, A296, $2197.6 \mathrm{~m}$. (d) Carbonate cemented tight diagenetic facies, H26, $2199.9 \mathrm{~m}$.

The movable fluid saturation of the clay mineral cemented microporous diagenetic facies sample is relatively small, 23.9\%, of which the movable pore space corresponding to the relaxation time greater than the $T_{2}$ cut-off value is $18.2 \%$, and the movable pore space corresponding to the $T_{2}$ cut-off value is $5.7 \%$. The $T_{2}$ spectrum curve before centrifugation is characterized by a single peak shape, and the $T_{2}$ spectrum curve shape after centrifugation mainly changes in the region greater than the $T_{2}$ cut-off value (Figure 5(c)).

The movable fluid saturation of the carbonate cemented tight diagenetic facies sample is the lowest at $12.69 \%$, of which the movable pore space corresponding to the relaxation time greater than the $T_{2}$ cut-off value is $7.1 \%$, and the movable pore space corresponding to the $T_{2}$ cut-off value is $5.6 \%$. The morphological characteristics of the $T_{2}$ spectrum curve before centrifugation showed a single peak shape, and the shape of the $T_{2}$ spectrum curve after centrifugation hardly changed significantly (Figure 5(d)).

According to the above research and analysis, it is found that the movable fluid saturation and movable fluid porosity of the sandstone core samples of the low permeability reservoirs in the study area are generally low and have a large distribution range, and the microscopic pore structure heterogeneity is strong and the difference is large. The $T_{2}$ cut-off value is generally low. Most of the samples before and after centrifugation are smaller than the $T_{2}$ cut-off value. The curve shape changes little. The area where the movable fluid 
saturation changes greatly is mainly the blue area, indicating the difference in the movable fluid saturation in the study area. It mainly depends on the degree of connectivity of the relatively large pore space corresponding to the relaxation time greater than the $T_{2}$ cut-off value, and the movable fluid saturation varies significantly between different diagenetic facies.

\section{Conclusions}

(1) The early compaction of diagenesis in the study area resulted in an average porosity loss rate of $50.62 \%$, the overall cementation caused a porosity loss rate of about $27.8 \%$, and the dissolution increased the secondary porosity to an average of $2.26 \%$. The porosity evolution characteristics of different diagenetic facies are obviously different, and the final calculated porosity of the residual chlorite-membrane intergranular-pore diagenetic facies is the largest, with an average of $12.28 \%$. The dissolution porosity of the feldspar dissolution diagenetic facies increases the most, with an average of $3.95 \%$. The clay mineral cemented microporous diagenetic facies lose the most porosity due to the middle-late cementation, with an average of $8.11 \%$. The carbonate cemented tight diagenetic facies lead to the smallest loss of porosity, while the early cementation leads to the largest loss of porosity, with an average of $17.12 \%$.

(2) There are obvious differences in pore throat radius distribution characteristics, movable fluid occurrence characteristics, and water drive characteristics of different diagenetic facies. The size distribution of the pore throat radius controls the seepage capacity. The larger the proportion of relatively large pore throats, the greater the permeability and the stronger the seepage capacity. The pore throat distribution with a radius greater than $R_{50} \sim R_{60}$ determines the permeability. The difference of movable fluid saturation mainly depends on the degree of connectivity of the relatively large pore space corresponding to the relaxation time greater than the $T_{2}$ cut-off value.

\section{Data Availability}

The underlying data supporting the results are from Changqing Oilfield Database.

\section{Conflicts of Interest}

The authors declare that they have no conflicts of interest.

\section{Acknowledgments}

This work was funded by National Science and Technology Major Project of the Ministry of Science and Technology of China (2017ZX05013-004 and 2017ZX05069-003), Open Foundation of Key Laboratory of Coal Resources Exploration and Comprehensive Utilization, Ministry of Natural Resources (KF2021-3), Shaanxi Provincial Key Research and Development Program (2021GY-140), Opening Foundation of Shaanxi Key Laboratory of Advanced Stimulation Technology for Oil \& Gas Reservoirs (20JS120), National Natural Science Foundation of China (51934005 and 52074226), and Young Science and Technology Talents Foundation of Shaanxi Province (2019KJXX-054).

\section{References}

[1] M. He, Q. Wang, and Q. Wu, "Innovation and future of mining rock mechanics," Journal of Rock Mechanics and Geotechnical Engineering, vol. 13, no. 1, pp. 1-21, 2021.

[2] C. Zhu, M.-C. He, M. Karakus, X.-H. Zhang, and Z. Guo, “The collision experiment between rolling stones of different shapes and protective cushion in open-pit mines," Journal of Mountain Science, vol. 18, no. 5, pp. 1391-1403, 2021.

[3] C. Zhu, M. He, M. Karakus, X. Zhang, and Z. Tao, "Numerical simulations of the failure process of anaclinal slope physical model and control mechanism of negative Poisson's ratio cable," Bulletin of Engineering Geology and the Environment, vol. 80 , no. 4 , pp. 3365-3380, 2021.

[4] F. Wu, R. Gao, J. Liu, and C. Li, "New fractional variable-order creep model with short memory," Applied Mathematics and Computation, vol. 380, Article ID 125278, 2020.

[5] F. Wu, H. Zhang, Q. Zou, C. Li, J. Chen, and R. Gao, "Viscoelastic-plastic damage creep model for salt rock based on fractional derivative theory," Mechanics of Materials, vol. 150, Article ID 103600, 2020.

[6] Q. Wang, Y. Wang, M. C. He et al., "Experimental research and application of automatically formed roadway without advance tunneling," Tunnelling and Underground Space Technology, vol. 114, no. 3, 2021.

[7] B. Li, R. Bao, Y. Wang, R. Liu, and C. Zhao, "Permeability evolution of two-dimensional fracture networks during shear under constant normal stiffness boundary conditions," Rock Mechanics and Rock Engineering, vol. 54, no. 3, pp. 1-20, 2021.

[8] C. N. Zou, R. K. Zhu, S. T. Wu et al., "Types, characteristics, genesis and prospects of conventional and unconventional hydrocarbon accumulations: taking tight oil and tight gas in China as an instance," Acta Petrolei Sinica, vol. 33, no. 2, pp. 173-187, 2012.

[9] H. Gao, M. Q. He, P. Y. Zhao, L. B. Dou, and C. Wang, "Comparison of geological characteristics of Chang 7 shale oil in Ordos basin and typical shale oil in north America," Petroleum Geology and Experiment, vol. 40, no. 2, pp. 133-140, 2018.

[10] X. P. Yang, W. Z. Zhao, C. N. Zou, and M. J. Chen, "Origin of low-permeability reservoir and distribution of favorable reservoir," Acta Petrol Sinica, vol. 28, no. 4, pp. 57-61, 2007.

[11] P. H. Nelson, "Pore-throat sizes in sandstones, tight sandstones, and shales," AAPG Bulletin, vol. 93, no. 3, pp. 329-340, 2009.

[12] R. G. Loucks, R. M. Reed, S. C. Ruppel, and D. M. Jarvie, "Morphology, genesis, and distribution of nanometer-scale pores in siliceous mudstones of the mississippian barnett shale," Journal of Sedimentary Research, vol. 79, no. 12, pp. 848-861, 2009.

[13] H. Yang, S. X. Li, and X. Y. Liu, "Characteristics and resource prospects of tight oil and shale oil in Ordos basin," Acta Petrolei Sinica, vol. 34, no. 1, pp. 1-11, 2013.

[14] Q. L. Guo, N. Wu, N. S. Chen, H. J. Ren, Z. Yang, and H. B. Xie, "An assessment of tight oil resource in 7th oil reservoirs of Yanchang formation Ordos basin," Acta Petrolei Sinica, vol. 38, no. 6, pp. 658-665, 2017.

[15] H. Wu, C. L. Zhang, Y. L. Ji et al., "Pore throat size characterization of tigh sandstone and its control on reservoir physicalp roperties: a case study of Yanchang formation, 
eastern Gansu, Ordos basin," Acta Petrolei Sinica, vol. 38, no. 8, pp. 876-887, 2017.

[16] Y. Yang, W. Li, and L. Ma, "Tectonic and stratigraphic controls of hydrocarbon systems in the Ordos basin: a multicycle cratonic basin in central China," AAPG Bulletin, vol. 89, no. 2, pp. 255-269, 2005.

[17] S. X. Li, X. Q. Deng, J. L. Pang, J. W. Lv, and X. Liu, "Relationship between petroleum accumulation of mesozoic and tectonic movement in Ordos basin," Acta Petrolei Sinica, vol. 28, no. 4, pp. 798-807, 2010.

[18] B. Bai, R. K. Zhu, S. T. Wu, J. W. Cui, T. Su, and T. T. Li, "New microthroat structural characterization techniques for unconventional tight hydrocarbon reservoir," China Petroleum Exploration, vol. 19, no. 3, pp. 78-86, 2015.

[19] Q. Wang, P. A. Peng, W. Z. Zhang, J. Z. Liu, and C. L. Yu, "Quantitative full-component hydrocarbon-generating simulation and crude oil mobility evaluation of shale in 7th member of Yanchang formation, Ordos basin," Acta Petrolei Sinica, vol. 3, no. 5, pp. 541-553, 2018.

[20] J. Yu, X. Yang, B. Li, X. J. Liu, and J. F. Tian, "A method of determining movable fluid saturation of tight oil reservoirs: a case study of tight oil reservoirs in seventh member of Yanchang formation in Heshui area," Petroleum Geology and Experiment, vol. 36, no. 6, pp. 767-772, 2014.

[21] R. E. Liu, F. J. Sun, X. F. Wei, X. Q. Shan, H. Zhao, and J. Lin, "Difference of reservoir microscopic features of the quartz sandstone and litharenite of the $2^{\text {nd }}$ member of Shanxi formation, upper paleozoic in middle east Ordos basin," Petroleum Exploration and Development, vol. 32, no. 5, pp. 56-58, 2005.

[22] B. S. Nabawy, Y. Géraud, P. Rochette, and N. Bur, "Porethroat characterization in highly porous and permeable sandstones," AAPG Bulletin, vol. 93, no. 6, pp. 719-739, 2009.

[23] W. M. Wang, H. K. Guo, and Z. H. Ye, "The evaluation of development potential in low permeability oilfield by the aid of NMR movable fluid detecting technology," Acta Petrolei Sinica, vol. 22, no. 6, pp. 40-44, 2001.

[24] K. Zheng, H. M. Xu, J. W. Chen, and Y. H. Wang, "Movable fluid study of low permeability reservoir with nuclear magnetic resonance technology," Geoence, vol. 27, no. 3, pp. 710-718, 2013.

[25] P. Li, W. Sun, B. Wu, Y. Gao, and K. Du, "Occurrence characteristics and influential factors of movable fluids in pores with different structures of Chang 63 reservoir, Huaqing oilfield, Ordos basin, China," Marine and Petroleum Geology, vol. 97, pp. 480-492, 2018.

[26] K. Al-Ramadan, S. Morad, J. N. Proust, and I. Al-Aasm, "Distribution of diagenetic alterations in siliciclastic shoreface deposits within a sequence stratigraphic framework: evidence from the upper jurassic, boulonnais, NW France," Journal of Sedimentary Research, vol. 75, no. 5, pp. 943-959, 2005.

[27] S. A. Stonecipher, "Applied sandstone diagenesis practical petrographic solutions for a variety of common exploration, development, and production problems," SEPM Short Course, vol. 50, p. 143, 2000.

[28] A. M. Wolela and E. H. Gierlowski-Kordesch, "Diagenetic history of fluvial and lacustrine sandstones of the hartford basin (triassic-jurassic), newark supergroup, USA," Sedimentary Geology, vol. 197, no. 1-2, pp. 99-126, 2007. 